\title{
LRRK2 and neuroinflammation: partners in crime in Parkinson's disease?
}

\author{
Isabella Russo ${ }^{*}$, Luigi Bubacco and Elisa Greggio*
}

\begin{abstract}
It is now well established that chronic inflammation is a prominent feature of several neurodegenerative disorders including Parkinson's disease (PD). Growing evidence indicates that neuroinflammation can contribute greatly to dopaminergic neuron degeneration and progression of the disease. Recent literature highlights that leucine-rich repeat kinase 2 (LRRK2), a kinase mutated in both autosomal-dominantly inherited and sporadic PD cases, modulates inflammation in response to different pathological stimuli. In this review, we outline the state of the art of LRRK2 functions in microglia cells and in neuroinflammation. Furthermore, we discuss the potential role of LRRK2 in cytoskeleton remodeling and vesicle trafficking in microglia cells under physiological and pathological conditions. We also hypothesize that LRRK2 mutations might sensitize microglia cells toward a pro-inflammatory state, which in turn results in exacerbated inflammation with consequent neurodegeneration.
\end{abstract}

Keywords: LRRK2, Neuroinflammation, Microglia, Neurodegeneration, Parkinson's disease, Dopaminergic neurons

\section{Introduction}

Leucine-rich repeat kinase 2 (LRRK2) is a large multidomain protein belonging to the family of mammalian ROCO (Ras Of COmplex) proteins, and characterized by the presence of an enzymatic core, comprising $\mathrm{ROC} /$ GTPase, COR (C-terminus of ROC) and serine threonine kinase domains, and by multiple protein-protein interaction domains including ankyrin and leucine-rich repeat motifs at the N-terminus, and WD40 repeats at the Cterminus [1,2]. Although the physiological functions of LRRK2 are still unclear, the presence of both a GTPase and a kinase domain suggest a role in intracellular signaling, and the existence of different protein binding domains points to an additional function as a scaffolding protein for the assembly of protein complexes [3].

Mutations in LRRK2 cause autosomal-dominantly inherited Parkinson's Disease, while more common variations can also act as risk factors for disease, accounting for $13 \%$ of all familial PD cases, and 1 to $2 \%$ of all sporadic PD cases $[1,4,5]$. Despite intensive research efforts, little is known about the pathogenic mechanism(s) of mutant LRRK2. Interestingly, LRRK2-associated PD is clinically and pathologically similar to sporadic PD, thus indicating

\footnotetext{
* Correspondence: isabella.russo@unipd.ti; elisa.greggio@unipd.it

Department of Biology, University of Padova, Via Ugo Bassi 58/B, 35121 Pad ova, Italy
}

overlapping pathways in both familial and sporadic PD [1]. Several mutations in LRRK2 clearly segregate with the disease, and, importantly, these mutations cluster within the two catalytic domains, suggesting that a change in enzymatic functions (GTPase and/or kinase) may mediate the pathogenic effects of LRRK2 [6]. R1441G/C/H mutations map to the ROC domain $[4,7,8]$, Y1669C to the COR domain [1], and I2020T and G2019S mutations to the kinase domain $[9,10]$. In this frame, the G2019S mutation is by far the most common pathogenic LRRK2 mutation, and is responsible for more than $10 \%$ of familial PD cases and 1 to $2 \%$ of sporadic PD cases [11]. Several studies have shown that of all the LRRK2 mutations, only the G2019S mutation consistently increases kinase activity [12-14]. Specifically, in vitro phosphorylation assays from independent studies showed an approximately three fold increase in kinase activity in comparison with wild-type protein, whereas ROC-COR mutations display inconsistent effects on kinase, but have significantly lower GTPase activity [15-18]. Conversely, the effect of the I2020T mutation on kinase activity is less clear, with studies observing both increased [19] and decreased [20,21] activity. However, the effects of LRRK2 mutations on kinase activity have been mainly examined in vitro by monitoring autophosphorylation or phosphorylation of model peptides, making it difficult to understand the real effects of mutations on LRRK2 
physiological functions. Interestingly, a recent paper by Sheng and colleagues reported that autophosphorylation on serine 1292 is a direct indicator of LRRK2 kinase activity in vivo, and that additional mutations, other than G2019S, appear to increase autophosphorylation at this site [22], consistent with an in vitro study focused on autophosphorylation [23]. Monitoring phosphorylation of serine 1292 in cells represents an important tool for future studies addressing pathways and signaling networks that relate to LRRK2 kinase function.

In the brain, LRRK2, both mRNA and protein, has been detected in specific regions including the cortex, striatum, hippocampus, and with substantial lower expression, in the substantia nigra pars compacta (SNpc) [24-26]. LRRK2 has been reported to localize within a wide range of vesicular and membranous structures, such as mitochondria, endoplasmic reticulum, and Golgi apparatus, as well as the endolysosomal system and synaptic vesicles [25,27-29]. Although LRRK2 protein is expressed in various brain cell types such as neurons, microglia, and astrocytes [30], the vast majority of studies to date have focused on investigating LRRK2 functions in neurons, being the relevant cell type that degenerates in PD. The physiological functions of LRRK2 in neuronal cells have been linked to vesicular trafficking [31,32], cytoskeletal dynamics [33,34], mitochondrial function [35,36], apoptosis [37], and regulation of the autophagy pathway [38-41]; however, how LRRK2 mutations cause neurodegeneration in PD is currently under debate.

\section{Effects of reactive microglia and neuroinflammation in the pathogenesis of PD}

It is now well established that chronic inflammation is a prominent feature of several neurodegenerative disorders, including PD $[42,43]$. The inflammatory response is driven by the activation of resident macrophages, local invasion of circulating immune cells, and production of cytokines, chemokines, and reactive oxygen species, all essential to recruit cells of the immune system to the compromised area [42]. Microglia cells, the resident macrophages of the brain, constitute the first barrier of the innate immune response in the brain, and are considered to be key players during neuroinflammation $[42,44,45]$. Microglia cells continually survey the microenvironment, and upon detection of abnormal changes in the surrounding tissue, they rapidly become activated, secrete inflammatory mediators, and migrate to the damaged area to eliminate pathogens or to phagocyte dead cells and/or aggregated proteins $[46,47]$. Although a well-regulated inflammatory process is essential for tissue repair and CNS integrity, an excessive and protracted inflammatory response can turn cytotoxic, leading to significant tissue and cellular damage, thus promoting the progression of the disease $[42,48]$.
It has been widely reported that chronic inflammation can contribute to the degeneration of dopaminergic neurons and to the progression of PD $[48,49]$. Elevated levels of pro-inflammatory cytokines (tumour necrosis factor (TNF)- $\alpha$, interferon (IFN)- $\gamma$, interleukin (IL)- $1 \beta$, and IL-6) have been found in the cerebrospinal fluid, striatum and SNpc of experimental animal models and of post-mortem brains from patients with PD [48-50]. Moreover, the presence of extensive proliferation of reactive and phagocytic macrophages positive for human leukocyte antigen (HLA) has been shown around dopaminergic neurons in the SNpc of patients with PD [51], in animal models, and in patients with parkinsonism after 1-methyl-4-phenyl-1,2,3,6-tetrahydropyridine (MPTP) exposure [52,53], further indicating that microglia cells and their mediators might lead to neuronal damage and degeneration $[54,55]$.

Microglia-mediated dopaminergic neurodegeneration is supported by numerous studies. In fact, this class of neurons exhibits a reduced antioxidant capacity and enhanced sensitivity to pro-inflammatory mediators, probably as a result of the high density of microglia cells present in SNpc compared to other brain regions [56-59]. Ouchi and colleagues reported that microglia activation in the midbrain is positively correlated with dopaminergic neuronal death and motor symptom severity in the early stage of PD [60], supporting the notion that reactive microglia exacerbate the progression of the disease.

Supporting evidence for a direct role of inflammation in PD has recently emerged from genome-wide association studies (GWAS). Specifically, polymorphisms in genes encoding inflammatory cytokines such as TNF- $\alpha$ and $I L-1 \beta$, and cell-surface human leukocyte antigen $(H L A)$ are associated with a higher risk of developing PD [61-64]. These genes are predominantly expressed in glial cells, and are directly involved in the inflammatory process [65]. Although it is still controversial whether inflammation is causative or a secondary effect of earlier pathological events of PD, there is an increasing recognition of neuroinflammation as a major player in the pathology of this disease.

Remarkably, LRRK2 has been identified by GWAS as one of the susceptibility genes for leprosy and possibly for Crohn's disease [66-68], two illnesses with a strong inflammatory component. Based on these genetic findings, a number of recent studies have explored the putative role of LRRK2 in microglia cells and the impact of LRRK2 mutations in the inflammatory response associated with PD.

\section{What is the role of LRRK2 in microglia cells?}

Microglia are highly dynamic cells with vastly branched and motile cell processes, which constantly screen the brain parenchyma, ready to detect any changes in the tissue [47]. In response to pathological stimuli such as lipopolysaccharide (LPS), aggregated proteins, or dead neurons, microglia 
cells switch from a resting and ramified phenotype into an ameboid, activated phenotype $[47,69,70]$. Once they have migrated toward a damaged area, they initiate a repairing program through the release of inflammatory mediators and the removal of debris by phagocytosis [71]. A number of LRRK2 pathways have been described in neuronal cells [72-74], but here we will discuss the potential roles of this protein in the physiological and pathological functions of microglia cells.

\section{Immune-related cellular pathways}

Recent findings indicate elevated LRRK2 mRNA and protein expression in immune cells, particularly in microglia and astrocytes from human and rodent brain $[30,75,76]$, and in peripheral blood mononuclear cells, mainly in B cells, dendritic cells, and macrophages [77,78]. Giesert et al. investigated potential LRRK2 mRNA splice variants in brain cells [26]; they observed that both neurons and astrocytes (but not microglia) express a transcript variant containing the alternative exon $42 \mathrm{a}$, which results in a premature stop codon and a predicted protein of 2152 amino acids long. This finding is intriguing, as it suggests that LRRK2 function(s) in microglia cells may be at least partly different from those exerted in other brain cell types.

Interestingly, Moehle and colleagues observed a robust induction of LRRK2 protein in microglia cells of mouse $\mathrm{SNpc}$ or striatum after LPS-induced inflammation [30]. Furthermore, in vitro studies reported increased LRRK2 protein expression in microglia cell cultures after an inflammatory stimulus induced by LPS or IFN- $\gamma$ [79], but not after HIV-1 Tat protein-induced inflammation [76]. In addition to increased expression levels, LRRK2 immunoprecipitated from LPS-inflamed brains was more active in in vitro autophosphorylation assays [30], possibly indicating that the protein is switched into an active conformation. Although the exact mechanism is not clear, two different studies reported that HIV-1 Tat protein-induced inflammation of BV2 cells or Toll-like receptor (TLR) agonists (but not TNF- $\alpha$ treatment of RAW264.7 macrophages) induced marked phosphorylation of LRRK2 at serines 910 and $935[76,80]$, a state that is possibly associated with an active LRRK2 form. Taken together, these data suggest that LRRK2 expression and enzymatic activity are required during an inflammatory response; however, the specific pathways and signaling cascades that LRRK2 orchestrates have not been characterized.

Additional studies further support a role for LRRK2 as regulator of inflammation. Murine microglia cells with inhibited or down-regulated LRRK2 showed attenuated levels of LPS-induced inflammatory mediators at the mRNA and protein level, including TNF- $\alpha$, IL- $1 \beta$, IL-6 and inducible nitric oxide synthase (iNOS) $[30,81]$. In particular, LRRK2 knockdown microglia exhibited a significant reduction of nuclear factor kappa B (NF- $k B$ ) transcriptional activity following TLR-mediated immune signaling induced by LPS, and an increase of DNA-binding activity of the NF- $\mathrm{KB}$ p50 inhibitor subunit [81]. As NF- $\mathrm{kB}$ activity is essential for induction of pro-inflammatory cytokines [82-84], LRRK2 might control its activation and the consequent transcription of pro-inflammatory mediators, through a yet undisclosed mechanism. In another study, Liu and colleagues demonstrated that LRRK2 can function as negative regulator of nuclear factor of activated $\mathrm{T}$ cells (NFAT) transcription factors, a class of molecules implicated in the inflammatory response in a large set of immune cells [85]. In particular, they observed that LRRK2 inhibits NFAT nuclear translocation in a TLR-independent manner, and thus inhibits the transcription of immune response genes via interaction with the NRON (noncoding (RNA) repressor of NFAT) complex in immune peripheral cells [62]. Although a significant amount of progress has been made, how LRRK2 modulates transcription factors and induction of inflammatory genes remains controversial and needs to be carefully explored.

Notably, Gillardon and colleagues [79] observed that LPS-activated microglia cells from LRRK2 R1441G knockin mice exhibited increased expression and secretion of pro-inflammatory cytokines and reduced expression of anti-inflammatory cytokines compared with wild-type control microglia cells. Interestingly, gene expression profiling of LRRK2 R1441G microglia cells under unstimulated conditions revealed that several cytokines, chemokines, and membrane receptors regulating microglia activation were significantly increased compared with wild-type cells, indicative of a basal sensitization toward a pro-inflammatory phenotype. In addition, conditioned medium from LPSstimulated LRRK2 R1441G microglia added to primary cortical neurons caused increased neuronal death compared with medium from wild-type LRRK2 microglia. Overall, these data indicate that LRRK2 is involved in the cellular pathways induced by inflammation, and that LRRK2 R1441G mutation might push microglia toward a pro-inflammatory state, which results, in turn, in exacerbated inflammation and consequent neurodegeneration in patients with PD (Figure 1).

Of note, Lopez de Maturana and colleagues recently reported the effects of pro-inflammatory LPS stimulus on epidermal cells from patients with PD who carried R1441G or G2019S LRRK2 mutations, and patients with idiopathic PD compared with controls [86]. Interestingly, these authors found that patient cells had a blunted response to LPS compared with control cells. However, whether immune cells respond to LPS priming in a similar manner remains to be determined.

\section{Cytoskeleton reorganization}

LRRK2 has been suggested to influence actin cytoskeleton and microtubule dynamics, and these functions 


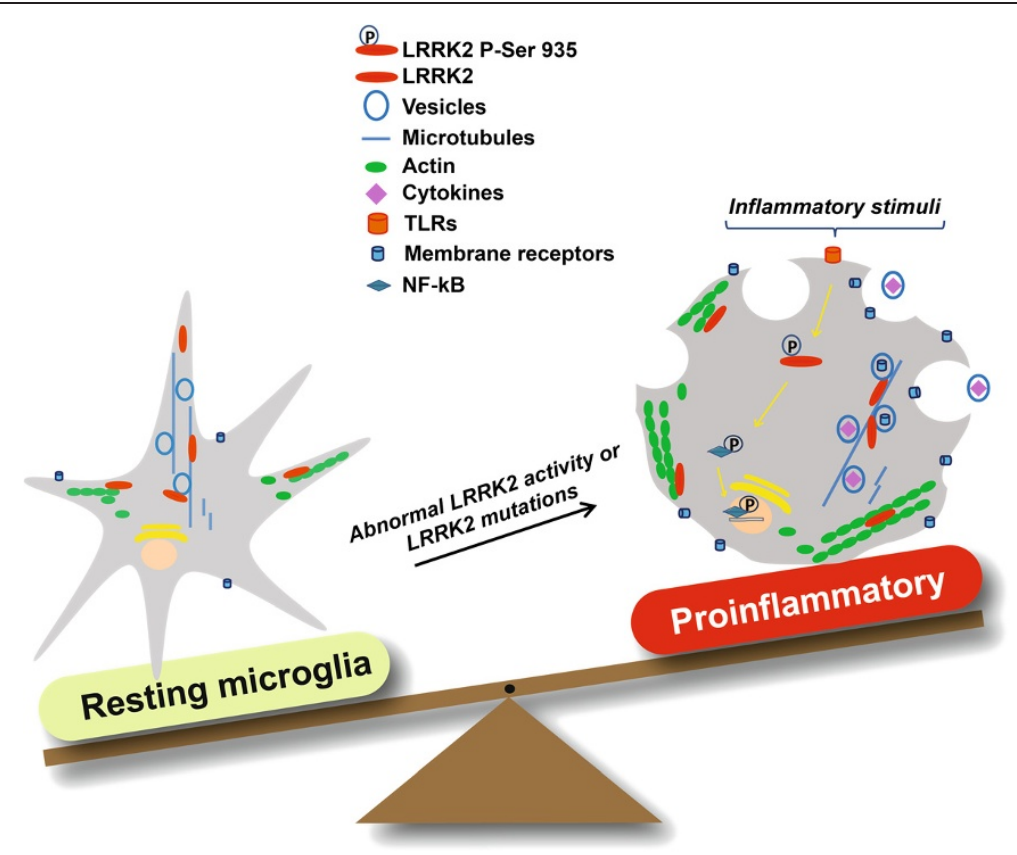

Figure 1 Abnormal activity of or mutations LRRK2 might push microglia cells toward a pro-inflammatory phenotype. Abnormal LRRK2 activity might modulate microglia cell activation and phagocytosis through hyperphosphorylation and hyperpolymerization of cytoskeleton components such as actin and $\beta$-tubulin. Moreover, LRRK2 might regulate the delivery of membrane receptors (CD11b and MHC- II) and inflammatory cytokines through regulation of transcription factors (such as NF-KB), and interaction and phoshorylation of vesicle-associated proteins such as Rab GTPase and NSF, thus driving microglia toward a reactive phenotype with enhanced cell activity and inflammation in response to inflammatory stimuli including LPS, environmental insults, and neuronal susceptibility.

might be implicated in the neuronal damage underlying PD [73,87-89]. Various studies have reported the involvement of LRRK2 kinase activity in neurite outgrowth and maintenance of neuronal processes. There seems to be general agreement that the LRRK2 G2019S mutation has an inhibitory effect on neurite outgrowth and branching [20,90-92]. In this context, Parisiadou and colleagues hypothesized that the G2019S mutation causes increased actin polymerization and ERM (ezrin, radixin, moesin) protein phosphorylation in neuronal filopodia, thus acting as a physical barrier that prevents the extensions of microtubule and leads, in turn, to inhibition of neuronal processes [73]. These observations find a link with the proposed function of LRRK2 in the context of the microtubule network. In particular, it was reported that LRRK2 interacts through its ROC/GTPase domain and phosphorylates neuronal $\beta$ tubulin both in vitro and in vivo, as demonstrated by reduced phosphorylation of $\beta$-tubulin immunoprecipitated from knockout compared with wild-type mouse brains $[34,89,93]$. Furthermore, in vitro LRRK2 enhances tubulin polymerization in the presence of microtubule-associated proteins $[89,94]$, and phosphorylates tubulin-associated Tau [95], whereas in vivo, Tau is hyperphosphorylated in brains from R1441G trangenic mice [96]. Taken together, these data indicate that LRRK2 regulates the organization of the actin cytoskeleton and microtubule assembly.
Cytoskeleton reorganization is also a critical step for brain macrophage functions. Indeed, the rapid changes in cell morphology and cell activity that microglia cells undertake upon activation are governed by microtubules and by actin cytoskeleton remodeling [87,97-99]. Even microglia motility is a process that results from coordinated changes in the actin cytoskeleton and in the formation of cellsubstrate adhesion sites. The actin cytoskeleton provides the driving force at the cell front, while the microtubule network regulates the rear retraction $[97,99]$. During migration, microglia cells exhibit long, thin extensions called filopodia, which are supported by tight and dynamic bundles of actin filaments that continuously polymerize and depolymerize to support the cell movement [97,100-104].

Supporting a role of LRRK2 in cytoskeleton reorganization during microglia activation, two recent studies reported that inflammatory stimuli failed to induce significant morphological changes of fine process extensions and cytoskeleton remodeling in LRRK2 knockdown or LRRK2 inhibitor-treated microglia cells [30,76]. Moreover, Moehle and colleagues observed in vitro that LRRK2 inhibition prevents microglial migration in response to ADP, a potent microglial chemoattractant [30]. Another study demonstrated that human LRRK2 G2019S and mouse LRRK2 knockout fibroblasts exhibit altered cell migration in culture, with LRRK2 G2019S fibroblasts migrating faster and 
LRRK2 knockout migrating slower compared with control cells [87]. As the G2019S mutation increases LRRK2 catalytic function, LRRK2 kinase activity appears to be required for cytoskeleton remodeling and for motility of microglia cells.

Microglia are the predominant phagocytes in the brain. They act as a surveillance system for microbes and pathological proteins, and remove apoptotic cells and cellular debris in the brain [70]. They engulf and digest microbes or pathological proteins by binding to them via specialized surface receptors (such as TLRs) and subsequently trapping them into a phagosome, which then fuses with a lysosome to be digested $[46,105]$. Phagocytosis induces dramatic changes in the shape and the movement of a cell, including extension of the membrane and actin filaments, through reorganization of the cytoskeleton [106]. Barcia and colleagues demonstrated using in vivo high-resolution imaging that the entire microglia cell body is involved in the formation of a phagocytic cup [107]. Moreover, imaging of fluorescent actin molecules during phagocytosis showed coordinated movement of the cytoskeleton in the cup, which is mediated by a combination of localized actin polymerization and depolymerization, together with the contraction of actin filament networks [108]. Interestingly, Marker et al. showed that LRRK2 might be involved in microglia phagocytosis. They found that pharmacological inhibition of LRRK2 attenuated microglial phagocytosis of fluorescent beads after an inflammatory stimulus. In addition, BV2-immortalized microglia cells co-cultured in the axonal compartment of primary neurons (to study phagocytosis of neuronal processes in the absence of cell bodies), and exposed to inflammatory conditions, completely phagocytosed and destroyed axonal arbors. By contrast, treatment of co-cultures with the LRRK2 inibitor IN-1 protected the axons and neuronal phagocytosis by clearing microglia [76].

Overall, these data suggest that LRRK2 regulates microglia activation, migration, and phagocytosis, although the molecular mechanisms underlying these processes are still unknown. One possibility is that LRRK2 orchestrates cytoskeletal components such as actin, tubulin. and ERM proteins, and that the pathological G2019S mutation causes hyperphosphorylation and hyperpolymerization of cytoskeleton components, which leads, in turn, to reactive microglia with enhanced cell activity, migration, and phagocytosis in response to pathological stimuli, thus contributing to the pathogenesis of PD (Figure 1).

\section{Vesicle trafficking}

Strong evidence supports a role for LRRK2 in the secretory and endocytic pathways. Multiple in vivo and in vitro studies have reported that LRRK2 overexpression or knockdown affects synaptic vesicle endocytosis and exocytosis $[32,109,110]$. In detail, LRRK2 modulates synaptic vesicle trafficking by interaction with pre-synaptic proteins such as actin, syntaxin, synaptic vesicle glycoprotein 2A (SV2A), $N$-ethylmaleimide-sensitive factor (NSF), and Synapsin I [31]; affects synaptic vesicles endocytosis through interaction with Rab5b and EndoA, critical components of the endocytic machinery [32,110]; and regulates the numbers of readily releasable vesicles and their release in hippocampal neurons by interaction and phosphorylation of Snapin protein [111]. Importantly, the G2019S and R1441G mutations were shown to increase the levels of dopamine receptor D1 on the membrane surface [112], supporting the notion that pathological LRRK2 activity might affect vesicle trafficking and release.

LRRK2 has also been reported to regulate the endocytic pathway involved in the autophagic-lysosomal process, an important clearance route for several aggregated or unfolded proteins. Interestingly, the LRRK2 Drosophila homolog interacts with Rab7, modulating the degradation of autophagosomes [27]. Human LRRK2 forms a complex with Rab7L1, an important component of the autophagiclysosomal pathway [113]. In addition, LRRK2 interacting with Rab5 might also affect the early step of autophagosome formation [114].

Vesicle trafficking in secretory and endocytic pathways are well described in microglia cells during cytokine release, delivery of membrane receptors to the cell membrane, and phagocytosis $[115,116]$. Transport of inflammation-induced cytokines (such as TNF- $\alpha$ and IL-6) from the endoplasmic reticulum to the cell surface occurs through the endosomal system, and relies on a complex array of trafficking machinery to ensure the accurate docking and fusion of carrier vesicles to their designated target membranes [117]. Delivery and internalization of membrane receptors in macrophages are essential for the regulation of cell activation [118], and their trafficking also occurs through endosomes. Notably, Rab7 is fundamental for the trafficking of receptor-containing vesicles involved in the inflammatory response [119], thus supporting the notion that LRRK2 might affect the expression of membrane receptors on microglia cells.

The endosomal pathway also plays a central role during phagocytosis. Macrophages, when in contact with pathogens or dying cells, initiate a sequence of membrane fusion events that culminate with the formation of a phagocytic cup, which is followed by the formation of a nascent phagosome around the ingested material, and its consequent internalization [120]. The phagosome is then reshaped to form the phagolysosome, where pathogens are degraded to produce antigenic peptides. Multiple soluble N-ethylmaleimide-sensitive factor attachment protein receptor (SNARE) proteins are required for the formation and the maturation of phagosome. Specifically, phagocytic cup formation is determined by fusion of the plasma membrane with intracellular organelles including recycling 
endosomes, late endosomes, and endoplasmic reticulum, which have a large amount of membrane and contain the appropriate SNARE and Rab GTPase proteins. It has been demonstrated that macrophages, when activated, regulate the expression of SNAREs and GTPases to provide a large set of proteins for membrane fusion, important for phagocytic cup formation [115].

Although a role for LRRK2 in vesicle trafficking in microglia cells has not been described, we speculate that LRRK2 activity may be important for the release of inflammatory mediators, delivery of membrane receptors, and phagocytotic processes. In particular, LRRK2 might regulate the components of the fusion machinery, such as its partner NSF [31] or Rab GTPase proteins, which have been shown to contribute to the fusion of vesicles containing inflammatory mediators, receptors, and pathogens to be eliminated. It should be noted that several receptors regulating microglial activation, such as major histocompatibility complex (MHC) class II and CD11b, which have also been observed to be up-regulated in brains of patients with PD [51,121,122], showed increased mRNA expression under basal conditions in transgenic microglia with LRRK2 R1441G mutation, thus suggesting that LRRK2 might affect the expression of these receptors. Moreover, when these cells were activated with LPS, the levels of cytokines/chemokines, proteins, and mRNAs massively increased compared with wild-type cultures [79], thus indicating that LRRK2 might play a key role in vesicle trafficking and release in microglia cells and might be important in switching these cells toward a pro-inflammatory phenotype (Figure 1).

\section{Conclusions}

Recent literature indicates that microglial LRRK2 plays a role in the cellular pathways induced by inflammatory stimuli. Based on its complex architecture with different functional domains, LRRK2 might be involved in more than one cellular process. Although a number of studies have analyzed the effects of LRRK2 kinase activity using different microglia-related readouts, such as morphological changes and inflammatory mediator release, evidence on how LRRK2 might affect these processes is currently lacking. Here we hypothesize that abnormal LRRK2 kinase activity, due to the presence of LRRK2 mutations, might modulate the phenotype of microglia through hyperpolymerization and hyperphosphorylation of cytoskeleton and vesicle components, thus pushing these cells toward a proinflammatory state. In this regard, Gillardon and colleagues observed that the LRRK2 R1441G mutation sensitizes microglia cells toward a neurotoxic state [79]. Similar to G2019S, the R1441G mutation causes an approximately 2.5-fold increase of serine 1292 autophosphorylation in cells overexpressing LRRK2-R1441G compared with wildtype LRRK2 [22], supporting the notion that the increased kinase activity of LRRK2 may push microglia toward a proinflammatory phenotype. One possibility is that the R1441G mutation increases kinase activity through its reduced GTP hydrolysis activity, although the cross-talk between GTPase and the kinase domain is currently unclear $[12,21,123]$.

The identification of microglia-specific kinase substrates, GTPase downstream effectors, and interactors, will provide valuable insight into the emerging function of LRRK2 in the regulation of neuroinflammation, with the potential of uncovering new molecular mechanisms underlying the pathogenesis of $\mathrm{PD}$, and consequently novel targets for drug treatments.

\section{Abbreviations}

CNS: Central nervous system; COR: C-terminus of ROC; ERM: ezrin, radixin, moesin; GWAS: Genome-wide association study; HLA: Human leukocyte antigen; iNOS: Inducible nitric oxide synthase; IFN: Interferon; IL: Interleukin; LPS: Lipopolysaccharide; LRRK2: Leucine-rich repeat kinase 2; MHC: Major histocompatibility complex; MPTP: 1-methyl-4-phenyl-1,2,3,6-tetrahydropyridine; NFAT: nuclear factor of activated T cells; NF-kB: nuclear factor kappa B; NRON: Noncoding (RNA) repressor of nuclear factor of activated T cells; NSF: N-ethylmaleimide-sensitive factor; PD: Parkinson's disease; ROC: Ras of complex proteins; SNARE: Soluble N-ethylmaleimide-sensitive factor attachment protein receptor; SNpc: Substantia nigra pars compacta; SV2A: Synaptic vesicle glycoprotein 2A; TNF: Tumor necrosis factor; TLR: Toll-like receptor.

\section{Competing interests}

The authors declare that they have no competing interest.

\section{Authors' contributions}

IR and EG conceived the paper; IR, LB, and EG wrote the paper. All authors read and approved the final manuscript.

\section{Acknowledgements}

This work was supported by the Michael J. Fox Foundation for Parkinson's Disease, the Italian Ministry of University and Research (Rientro dei Cervelli, Incentivazione alla mobilità di studiosi stranieri e italiani residenti all'estero to EG), and the CARIPLO Foundation (grant number 2011-0540). The financial support of Telethon - Italy (grant number GGP12237) is gratefully acknowledged.

Received: 31 December 2013 Accepted: 25 February 2014 Published: 21 March 2014

\section{References}

1. Paisán-Ruíz C, Jain S, Evans EW, Gilks WP, Simón J, van der Brug M, López de Munain A, Aparicio S, Gil AM, Khan N, Johnson J, Martinez JR, Nicholl D, Carrera IM, Pena AS, de Silva R, Lees A, Martí-Massó JF, Pérez-Tur J, Wood $N W$, Singleton $A B$ : Cloning of the gene containing mutations that cause PARK8-linked Parkinson's disease. Neuron 2004, 44:595-600.

2. Marin I: The Parkinson disease gene LRRK2: evolutionary and structural insights. Mol Biol Evol 2006, 23:2423-2433.

3. Bosgraaf L, Van Haastert PJ: Roc, a Ras/GTPase domain in complex proteins. Biochim Biophys Acta 2003, 1643:5-10.

4. Zimprich A, Biskup S, Leitner $P$, Lichtner $P$, Farrer M, Lincoln S, Kachergus J Hulihan M, Uitti RJ, Calne DB, Stoessl AJ, Pfeiffer RF, Patenge N, Carbajal IC, Vieregge P, Asmus F, Müller-Myhsok B, Dickson DW, Meitinger T, Strom TM, Wszolek ZK, Gasser T: Mutations in LRRK2 cause autosomal-dominant parkinsonism with pleomorphic pathology. Neuron 2004, 44:601-607.

5. Simón-Sánchez J, Schulte C, Bras JM, Sharma M, Gibbs JR, Berg D, Paisan-Ruiz C, Lichtner P, Scholz SW, Hernandez DG, Krüger R, Federoff M, Klein C, Goate A, Perlmutter J, Bonin M, Nalls MA, Illig T, Gieger C, Houlden H, Steffens M, Okun MS, Racette BA, Cookson MR, Foote KD, Fernandez HH, Traynor BJ, Schreiber S, Arepalli $S$, Zonozi R, et al: Genome-wide association study reveals genetic risk underlying Parkinson's disease. Nat Genet 2009, 41:1308-1312. 
6. Gomez-Suaga P, Fdez E, Blanca Ramirez M, Hilfiker S: A link between autophagy and the pathophysiology of LRRK2 in Parkinson's disease. Parkinsons Dis 2012, 2012:324521

7. Haugarvoll K, Rademakers R, Kachergus JM, Nuytemans K, Ross OA, Gibson JM, Tan EK, Gaig C, Tolosa E, Goldwurm S, Guidi M, Riboldazzi G, Brown L, Walter U, Benecke R, Berg D, Gasser T, Theuns J, Pals P, Cras P, De Deyn PP, Engelborghs S, Pickut B, Uitti RJ, Foroud T, Nichols WC, Hagenah J, Klein C, Samii A, Zabetian CP, et al: Lrrk2 R1441C parkinsonism is clinically similar to sporadic Parkinson disease. Neurology 2008, 70:1456-1460.

8. Kumari U, Tan EK: LRRK2 in Parkinson's disease: genetic and clinical studies from patients. FEBS J 2009, 276:6455-6463.

9. Funayama M, Hasegawa K, Ohta E, Kawashima N, Komiyama M, Kowa H, Tsuji S, Obata F: An LRRK2 mutation as a cause for the parkinsonism in the original PARK8 family. Ann Neurol 2005, 57:918-921.

10. Gilks WP, Abou-Sleiman PM, Gandhi S, Jain S, Singleton A, Lees AJ, Shaw K, Bhatia KP, Bonifati V, Quinn NP, Lynch J, Healy DG, Holton JL, Revesz T, Wood NW: A common LRRK2 mutation in idiopathic Parkinson's disease. Lancet 2005, 365:415-416.

11. Goldwurm S, Di Fonzo A, Simons EJ, Rohé CF, Zini M, Canesi M, Tesei S, Zecchinelli A, Antonini A, Mariani C, Meucci N, Sacilotto G, Sironi F, Salani G, Ferreira J, Chien HF, Fabrizio E, Vanacore N, Dalla Libera A, Stocchi F, Diroma C, Lamberti P, Sampaio C, Meco G, Barbosa E, Bertoli-Avella AM, Breedveld GJ, Oostra BA, Pezzoli G, Bonifati V: The G6055A (G2019S) mutation in LRRK2 is frequent in both early and late onset Parkinson's disease and originates from a common ancestor. J Med Genet 2005, 42:e65.

12. West AB, Moore DJ, Biskup S, Bugayenko A, Smith WW, Ross CA, Dawson VL, Dawson TM: Parkinson's disease-associated mutations in leucine-rich repeat kinase 2 augment kinase activity. Proc Natl Acad Sci USA 2005, 102:16842-16847.

13. Luzon-Toro B, de la Torre RE, Delgado A, Perez-Tur J, Hilfiker S: Mechanistic insight into the dominant mode of the Parkinson's disease-associated G2019S LRRK2 mutation. Hum Mol Genet 2007, 16:2031-2039.

14. Anand VS, Reichling $\sqcup$, Lipinski K, Stochaj W, Duan W, Kelleher K, Pungaliya P, Brown EL, Reinhart PH, Somberg R, Hirst WD, Riddle SM, Braithwaite SP: Investigation of leucine-rich repeat kinase 2: enzymological properties and novel assays. FEBS J 2009, 276:466-478.

15. Xiong Y, Dawson VL, Dawson TM: LRRK2 GTPase dysfunction in the pathogenesis of Parkinson's disease. Biochem Soc Trans 2012, 40:1074-1079.

16. Greggio E, Cookson MR: Leucine-rich repeat kinase 2 mutations and Parkinson's disease: three questions. ASN Neuro 2009, 1:13-24.

17. Daniels V, Vancraenenbroeck R, Law BM, Greggio E, Lobbestael E, Gao F, De Maeyer M, Cookson MR, Harvey K, Baekelandt V, Taymans JM: Insight into the mode of action of the LRRK2 Y1699C pathogenic mutant. J Neurochem 2011, 116:304-315.

18. Li Y, Dunn L, Greggio E, Krumm B, Jackson GS, Cookson MR, Lewis PA, Deng J: The R1441C mutation alters the folding properties of the ROC domain of LRRK2. Biochim Biophys Acta 2009, 1792:1194-1197.

19. Gloeckner CJ, Kinkl N, Schumacher A, Braun RJ, O'Neill E, Meitinger T, Kolch W, Prokisch $\mathrm{H}$, Ueffing M: The Parkinson disease causing LRRK2 mutation I2020T is associated with increased kinase activity. Hum Mol Genet 2006, 15:223-232.

20. Jaleel M, Nichols RJ, Deak M, Campbell DG, Gillardon F, Knebel A, Alessi DR: LRRK2 phosphorylates moesin at threonine-558: characterization of how Parkinson's disease mutants affect kinase activity. Biochem J 2007, 405:307-317.

21. Ito G, Okai T, Fujino G, Takeda K, Ichijo H, Katada T, Iwatsubo T: GTP binding is essential to the protein kinase activity of LRRK2, a causative gene product for familial Parkinson's disease. Biochemistry 2007, 46:1380-1388.

22. Sheng Z, Zhang S, Bustos D, Kleinheinz T, Le Pichon CE, Dominguez SL, Solanoy HO, Drummond J, Zhang X, Ding X, Cai F, Song Q, Li X, Yue Z, van der Brug MP, Burdick DJ, Gunzner-Toste J, Chen H, Liu X, Estrada AA, Sweeney ZK, Scearce-Levie K, Moffat JG, Kirkpatrick DS, Zhu H: Ser1292 autophosphorylation is an indicator of LRRK2 kinase activity and contributes to the cellular effects of PD mutations. Sci Transl Med 2012, 4:164ra161.

23. West AB, Moore DJ, Choi C, Andrabi SA, Li X, Dikeman D, Biskup S, Zhang Z, Lim KL, Dawson VL, Dawson TM: Parkinson's disease-associated mutations in LRRK2 link enhanced GTP-binding and kinase activities to neuronal toxicity. Hum Mol Genet 2007, 16:223-232.

24. Han BS, lacovitti L, Katano T, Hattori N, Seol W, Kim KS: Expression of the LRRK2 gene in the midbrain dopaminergic neurons of the substantia nigra. Neurosci Lett 2008, 442:190-194.
25. Biskup S, Moore DJ, Celsi F, Higashi S, West AB, Andrabi SA, Kurkinen K, Yu SW, Savitt JM, Waldvogel HJ, Faull RL, Emson PC, Torp R, Ottersen OP, Dawson TM, Dawson VL: Localization of LRRK2 to membranous and vesicular structures in mammalian brain. Ann Neurol 2006, 60:557-569.

26. Giesert F, Hofmann A, Burger A, Zerle J, Kloos K, Hafen U, Ernst L, Zhang J, Vogt-Weisenhorn DM, Wurst W: Expression analysis of Lrrk1, Lrrk2 and Lrrk2 splice variants in mice. PLOS One 2013, 8:e63778.

27. Dodson MW, Zhang T, Jiang C, Chen S, Guo M: Roles of the Drosophila LRRK2 homolog in Rab7-dependent lysosomal positioning. Hum Mol Genet 2012, 21:1350-1363.

28. Alegre-Abarrategui J, Christian H, Lufino MM, Mutihac R, Venda LL, Ansorge O, Wade-Martins R: LRRK2 regulates autophagic activity and localizes to specific membrane microdomains in a novel human genomic reporter cellular model. Hum Mol Genet 2009, 18:4022-4034.

29. Belluzzi E, Greggio E, Piccoli G: Presynaptic dysfunction in Parkinson's disease: a focus on LRRK2. Biochem Soc Trans 2012, 40:1111-1116.

30. Moehle MS, Webber PJ, Tse T, Sukar N, Standaert DG, DeSilva TM, Cowell RM, West AB: LRRK2 inhibition attenuates microglial inflammatory responses. J Neurosci 2012, 32:1602-1611.

31. Piccoli G, Condliffe SB, Bauer M, Giesert F, Boldt K, De Astis S, Meixner A, Sarioglu H, Vogt-Weisenhorn DM, Wurst W, Gloeckner CJ, Matteoli M, Sala C, Ueffing M: LRRK2 controls synaptic vesicle storage and mobilization within the recycling pool. J Neurosci 2011, 31:2225-2237.

32. Matta S, Van Kolen K, da Cunha R, van den Bogaart G, Mandemakers W, Miskiewicz K, De Bock PJ, Morais VA, Vilain S, Haddad D, Delbroek L, Swerts J, Chávez-Gutiérrez L, Esposito G, Daneels G, Karran E, Holt M, Gevaert K, Moechars DW, De Strooper B, Verstreken P: LRRK2 controls an EndoA phosphorylation cycle in synaptic endocytosis. Neuron 2012, 75:1008-1021.

33. Kett LR, Boassa D, Ho CC, Rideout HJ, Hu J, Terada M, Ellisman M, Dauer WT: LRRK2 Parkinson disease mutations enhance its microtubule association. Hum Mol Genet 2012, 21:890-899

34. Law BM, Spain VA, Leinster VH, Chia R, Beilina A, Cho HJ, Taymans JM, Urban MK, Sancho RM, Ramírez MB, Biskup S, Baekelandt V, Cai H, Cookson MR, Berwick DC, Harvey K: A direct interaction between leucine-rich repeat kinase 2 and specific beta-tubulin isoforms regulates tubulin acetylation J Biol Chem 2013, 289:895-908.

35. Papkovskaia TD, Chau KY, Inesta-Vaquera F, Papkovsky DB, Healy DG, Nishio K, Staddon J, Duchen MR, Hardy J, Schapira AH, Cooper JM: G2019S leucine-rich repeat kinase 2 causes uncoupling protein-mediated mitochondrial depolarization. Hum Mol Genet 2012, 21:4201-4213.

36. Wang X, Yan MH, Fujioka H, Liu J, Wilson-Delfosse A, Chen SG, Perry G, Casadesus $G$, Zhu X: LRRK2 regulates mitochondrial dynamics and function through direct interaction with DLP1. Hum Mol Genet 2012, 21:1931-1944.

37. Ho CC, Rideout HJ, Ribe E, Troy CM, Dauer WT: The Parkinson disease protein leucine-rich repeat kinase 2 transduces death signals via Fas-associated protein with death domain and caspase- 8 in a cellular model of neurodegeneration. J Neurosci 2009, 29:1011-1016.

38. Plowey ED, Cherra SJ 3rd, Liu YJ, Chu CT: Role of autophagy in G2019S LRRK2-associated neurite shortening in differentiated SH-SY5Y cells. J Neurochem 2008, 105:1048-1056.

39. Gomez-Suaga P, Luzon-Toro B, Churamani D, Zhang L, Bloor-Young D, Patel S, Woodman PG, Churchill GC, Hilfiker S: Leucine-rich repeat kinase 2 regulates autophagy through a calcium-dependent pathway involving NAADP. Hum Mol Genet 2012, 21:511-525.

40. Manzoni C, Mamais A, Dihanich S, Abeti R, Soutar MP, Plun-Favreau H, Giunti P, Tooze SA, Bandopadhyay R, Lewis PA: Inhibition of LRRK2 kinase activity stimulates macroautophagy. Biochim Biophys Acta 2013, 1833:2900-2910.

41. Orenstein SJ, Kuo SH, Tasset I, Arias E, Koga H, Fernandez-Carasa I, Cortes E, Honig LS, Dauer W, Consiglio A, Raya A, Sulzer D, Cuervo AM: Interplay of LRRK2 with chaperone-mediated autophagy. Nat Neurosci 2013, 16:394-406.

42. Russo I, Barlati S, Bosetti F: Effects of neuroinflammation on the regenerative capacity of brain stem cells. J Neurochem 2011, 116:947-956.

43. Pradhan S, Andreasson K: Commentary: progressive inflammation as a contributing factor to early development of Parkinson's disease. Exp Neurol 2013, 241:148-155.

44. Russo I, Amornphimoltham P, Weigert R, Barlati S, Bosetti F: Cyclooxygenase- 1 is involved in the inhibition of hippocampal neurogenesis after lipopolysaccharide-induced neuroinflammation. Cell Cycle 2011, 10:2568-2573.

45. Russo I, Caracciolo L, Tweedie D, Choi SH, Greig NH, Barlati S, Bosetti F: 3,6'Dithiothalidomide, a new TNF-alpha synthesis inhibitor, attenuates the 
effect of Abeta1-42 intracerebroventricular injection on hippocampal neurogenesis and memory deficit. J Neurochem 2012, 122:1181-1192.

46. Neumann H, Kotter MR, Franklin RJ: Debris clearance by microglia: an essential link between degeneration and regeneration. Brain 2009, 132:288-295.

47. Nimmerjahn A, Kirchhoff F, Helmchen F: Resting microglial cells are highly dynamic surveillants of brain parenchyma in vivo. Science 2005, 308:1314-1318.

48. Gao HM, Hong JS: Why neurodegenerative diseases are progressive: uncontrolled inflammation drives disease progression. Trends Immunol 2008, 29:357-365.

49. Hirsch EC, Hunot S: Neuroinflammation in Parkinson's disease: a target for neuroprotection? Lancet Neurol 2009, 8:382-397.

50. Mogi M, Harada M, Riederer P, Narabayashi H, Fujita K, Nagatsu T: Tumor necrosis factor-alpha (TNF-alpha) increases both in the brain and in the cerebrospinal fluid from parkinsonian patients. Neurosci Lett 1994, 165:208-210.

51. McGeer PL, Itagaki S, Boyes BE, McGeer EG: Reactive microglia are positive for HLA-DR in the substantia nigra of Parkinson's and Alzheimer's disease brains. Neurology 1988, 38:1285-1291.

52. Hurley SD, O'Banion MK, Song DD, Arana FS, Olschowka JA, Haber SN: Microglial response is poorly correlated with neurodegeneration following chronic, low-dose MPTP administration in monkeys. Exp Neurol 2003, 184:659-668.

53. Langston JW, Forno LS, Tetrud J, Reeves AG, Kaplan JA, Karluk D: Evidence of active nerve cell degeneration in the substantia nigra of humans years after 1-methyl-4-phenyl-1,2,3,6-tetrahydropyridine exposure. Ann Neurol 1999, 46:598-605.

54. Sriram K, Miller DB, O'Callaghan JP: Minocycline attenuates microglial activation but fails to mitigate striatal dopaminergic neurotoxicity: role of tumor necrosis factor-alpha. J Neurochem 2006, 96:706-718.

55. Aloisi F: Immune function of microglia. Glia 2001, 36:165-179.

56. Jenner P, Olanow CW: Understanding cell death in Parkinson's disease. Ann Neurol 1998, 44:S72-S84.

57. Whitton PS: Inflammation as a causative factor in the aetiology of Parkinson's disease. Br J Pharmacol 2007, 150:963-976.

58. Tansey MG, Goldberg MS: Neuroinflammation in Parkinson's disease: its role in neuronal death and implications for therapeutic intervention. Neurobiol Dis 2010, 37:510-518.

59. Russo I, Bubacco L, Greggio E: Exosomes-associated neurodegeneration and progression of Parkinson's disease. Am J Neurodegener Dis 2012, 1:217-225.

60. Ouchi Y, Yagi S, Yokokura M, Sakamoto M: Neuroinflammation in the living brain of Parkinson's disease. Parkinsonism Relat Disord 2009, 15(Suppl 3):S200-S204.

61. Hamza TH, Zabetian CP, Tenesa A, Laederach A, Montimurro J, Yearout D, Kay DM, Doheny KF, Paschall J, Pugh E, Kusel VI, Collura R, Roberts J, Griffith A, Samii A, Scott WK, Nutt J, Factor SA, Payami H: Common genetic variation in the HLA region is associated with late-onset sporadic Parkinson's disease. Nat Genet 2010, 42:781-785

62. Ahmed I, Tamouza R, Delord M, Krishnamoorthy R, Tzourio C, Mulot C, Nacfer M, Lambert JC, Beaune P, Laurent-Puig P, Loriot MA, Charron D, Elbaz A: Association between Parkinson's disease and the HLA-DRB1 locus. Mov Disord 2012, 27:1104-1110.

63. Bialecka M, Klodowska-Duda G, Kurzawski M, Slawek J, Gorzkowska A, Opala G, Bialecki P, Sagan L, Drozdzik M: Interleukin-10 (IL10) and tumor necrosis factor alpha (TNF) gene polymorphisms in Parkinson's disease patients. Parkinsonism Relat Disord 2008, 14:636-640.

64. Wahner AD, Sinsheimer JS, Bronstein JM, Ritz B: Inflammatory cytokine gene polymorphisms and increased risk of Parkinson disease. Arch Neurol 2007, 64:836-840.

65. Chung CY, Seo H, Sonntag KC, Brooks A, Lin L, Isacson O: Cell type-specific gene expression of midbrain dopaminergic neurons reveals molecules involved in their vulnerability and protection. Hum Mol Genet 2005, 14:1709-1725.

66. Zhang FR, Huang W, Chen SM, Sun LD, Liu H, Li Y, Cui Y, Yan XX, Yang HT, Yang RD, Chu TS, Zhang C, Zhang L, Han JW, Yu GQ, Quan C, Yu YX, Zhang Z, Shi BQ, Zhang LH, Cheng H, Wang CY, Lin Y, Zheng HF, Fu XA, Zuo XB, Wang $Q$, Long $H$, Sun YP, Cheng YL, et al: Genomewide association study of leprosy. N Engl J Med 2009, 361:2609-2618.

67. Umeno J, Asano K, Matsushita T, Matsumoto T, Kiyohara Y, lida M, Nakamura Y, Kamatani N, Kubo M: Meta-analysis of published studies identified eight additional common susceptibility loci for Crohn's disease and ulcerative colitis. Inflamm Bowel Dis 2011, 17:2407-2415.

68. Barrett JC, Hansoul S, Nicolae DL, Cho JH, Duerr RH, Rioux JD, Brant SR, Silverberg MS, Taylor KD, Barmada MM, Bitton A, Dassopoulos T, Datta LW, Green T, Griffiths AM, Kistner EO, Murtha MT, Regueiro MD, Rotter II, Schumm LP, Steinhart AH, Targan SR, Xavier RJ, NIDDK IBD Genetics Consortium, Libioulle C, Sandor C, Lathrop M, Belaiche J, Dewit O, Gut I, et al: Genome-wide association defines more than 30 distinct susceptibility loci for Crohn's disease. Nat Genet 2008, 40:955-962.

69. Ohsawa K, Kohsaka S: Dynamic motility of microglia: purinergic modulation of microglial movement in the normal and pathological brain. Glia 2011, 59:1793-1799.

70. Garden GA, Moller T: Microglia biology in health and disease. J Neuroimmune Pharmacol 2006, 1:127-137.

71. Abd-El-Basset EM, Abd-El-Barr MM: Effect of interleukin-1beta on the expression of actin isoforms in cultured mouse astroglia. Anat Rec (Hoboken) 2011, 294:16-23.

72. Cookson MR: The role of leucine-rich repeat kinase 2 (LRRK2) in Parkinson's disease. Nat Rev Neurosci 2010, 11:791-797.

73. Parisiadou L, Cai H: LRRK2 function on actin and microtubule dynamics in Parkinson disease. Commun Integr Biol 2010, 3:396-400.

74. Berwick DC, Harvey K: LRRK2 signaling pathways: the key to unlocking neurodegeneration? Trends Cell Biol 2011, 21:257-265.

75. Miklossy J, Arai T, Guo JP, Klegeris A, Yu S, McGeer EG, McGeer PL: LRRK2 expression in normal and pathologic human brain and in human cell lines. J Neuropathol Exp Neurol 2006, 65:953-963.

76. Marker DF, Puccini JM, Mockus TE, Barbieri J, Lu SM, Gelbard HA: LRRK2 kinase inhibition prevents pathological microglial phagocytosis in response to HIV-1 Tat protein. J Neuroinflammation 2012, 9:261.

77. Hakimi M, Selvanantham T, Swinton E, Padmore RF, Tong Y, Kabbach G, Venderova K, Girardin SE, Bulman DE, Scherzer CR, LaVoie MJ, Gris D, Park DS, Angel JB, Shen J, Philpott DJ, Schlossmacher MG: Parkinson's diseaselinked LRRK2 is expressed in circulating and tissue immune cells and upregulated following recognition of microbial structures. J Neural Transm 2011, 118:795-808.

78. Thevenet J, Pescini Gobert R, van Huijsduijnen Hooft R, Wiessner C, Sagot $Y J$ : Regulation of LRRK2 expression points to a functional role in human monocyte maturation. PLoS One 2011, 6:e21519.

79. Gillardon F, Schmid R, Draheim H: Parkinson's disease-linked leucine-rich repeat kinase 2 (R1441G) mutation increases proinflammatory cytokine release from activated primary microglial cells and resultant neurotoxicity. Neuroscience 2012, 208:41-48.

80. Dzamko N, Inesta-Vaquera F, Zhang J, Xie C, Cai H, Arthur S, Tan L, Choi H, Gray N, Cohen P, Pedrioli P, Clark K, Alessi DR: The IkappaB kinase family phosphorylates the Parkinson's disease kinase LRRK2 at Ser935 and Ser910 during Toll-like receptor signaling. PLoS One 2012, 7:e39132.

81. Kim B, Yang MS, Choi D, Kim JH, Kim HS, Seol W, Choi S, Jou I, Kim EY, Joe $\mathrm{EH}$ : Impaired inflammatory responses in murine Lrrk2-knockdown brain microglia. PLoS One 2012, 7:e34693.

82. Choi SH, Langenbach R, Bosetti F: Genetic deletion or pharmacological inhibition of cyclooxygenase- 1 attenuate lipopolysaccharide-induced inflammatory response and brain injury. FASEB J 2008, 22:1491-1501.

83. Lee M: Neurotransmitters and microglial-mediated neuroinflammation. Curr Protein Pept Sci 2013, 14:21-32.

84. Mogi M, Togari A, Kondo T, Mizuno Y, Komure O, Kuno S, Ichinose H, Nagatsu T: Caspase activities and tumor necrosis factor receptor R1 (p55) level are elevated in the substantia nigra from parkinsonian brain. J Neural Transm 2000, 107:335-341.

85. Liu Z, Lee J, Krummey S, Lu W, Cai H, Lenardo MJ: The kinase LRRK2 is a regulator of the transcription factor NFAT that modulates the severity of inflammatory bowel disease. Nat Immunol 2011, 12:1063-1070.

86. de Maturana LR, Aguila JC, Sousa A, Vazquez N, Del Rio P, Aiastui A, Gorostidi A, de Munain LA, Sanchez-Pernaute R: Leucine-rich repeat kinase 2 modulates cyclooxygenase 2 and the inflammatory response in idiopathic and genetic Parkinson's disease. Neurobiol Aging 2014, 5:1116-1124.

87. Caesar M, Zach S, Carlson CB, Brockmann K, Gasser T, Gillardon F: Leucinerich repeat kinase 2 functionally interacts with microtubules and kinasedependently modulates cell migration. Neurobiol Dis 2013, 54:280-288.

88. Meixner A, Boldt K, Van Troys M, Askenazi M, Gloeckner CJ, Bauer M, Marto JA, Ampe C, Kinkl N, Ueffing M: A QUICK screen for Lrrk2 interaction 
partners-leucine-rich repeat kinase 2 is involved in actin cytoskeleton dynamics. Mol Cell Proteomics 2011, 10:M110 001172.

89. Gillardon F: Leucine-rich repeat kinase 2 phosphorylates brain tubulin-beta isoforms and modulates microtubule stability-a point of convergence in parkinsonian neurodegeneration? J Neurochem 2009, 110:1514-1522.

90. MacLeod D, Dowman J, Hammond R, Leete T, Inoue K, Abeliovich A: The familial Parkinsonism gene LRRK2 regulates neurite process morphology. Neuron 2006, 52:587-593.

91. Parisiadou L, Xie C, Cho HJ, Lin X, Gu XL, Long CX, Lobbestael E, Baekelandt V, Taymans JM, Sun L, Cai H: Phosphorylation of ezrin/radixin/moesin proteins by LRRK2 promotes the rearrangement of actin cytoskeleton in neuronal morphogenesis. J Neurosci 2009, 29:13971-13980.

92. Sepulveda B, Mesias R, Li X, Yue Z, Benson DL: Short- and long-term effects of LRRK2 on axon and dendrite growth. PLoS One 2013, 8:e61986.

93. Gandhi PN, Wang X, Zhu X, Chen SG, Wilson-Delfosse AL: The Roc domain of leucine-rich repeat kinase 2 is sufficient for interaction with microtubules. J Neurosci Res 2008, 86:1711-1720.

94. Lin X, Parisiadou L, Gu XL, Wang L, Shim H, Sun L, Xie C, Long CX, Yang WJ, Ding J, Chen ZZ, Gallant PE, Tao-Cheng JH, Rudow G, Troncoso JC, Liu Z, Li $\mathrm{Z}$, Cai H: Leucine-rich repeat kinase 2 regulates the progression of neuropathology induced by Parkinson's-disease-related mutant alpha-synuclein. Neuron 2009, 64:807-827.

95. Kawakami F, Yabata T, Ohta E, Maekawa T, Shimada N, Suzuki M, Maruyama H, Ichikawa T, Obata F: LRRK2 phosphorylates tubulin-associated tau but not the free molecule: LRRK2-mediated regulation of the tau-tubulin association and neurite outgrowth. PLOS One 2012, 7:e30834

96. Li Y, Liu W, Oo TF, Wang L, Tang Y, Jackson-Lewis V, Zhou C, Geghman K, Bogdanov M, Przedborski S, Beal MF, Burke RE, Li C: Mutant LRRK2(R1441G) BAC transgenic mice recapitulate cardinal features of Parkinson's disease. Nat Neurosci 2009, 12:826-828.

97. Wehrle-Haller B, Imhof BA: Actin, microtubules and focal adhesion dynamics during cell migration. Int J Biochem Cell Biol 2003, 35:39-50.

98. Stuart LM, Bell SA, Stewart CR, Silver JM, Richard J, Goss JL, Tseng AA, Zhang A, El Khoury JB, Moore KJ: CD36 signals to the actin cytoskeleton and regulates microglial migration via a p130Cas complex. J Biol Chem 2007, 282:27392-27401.

99. Gardel ML, Schneider IC, Aratyn-Schaus Y, Waterman CM: Mechanical integration of actin and adhesion dynamics in cell migration. Annu Rev Cell Dev Biol 2010, 26:315-333.

100. Small JV, Stradal T, Vignal E, Rottner K: The lamellipodium: where motility begins. Trends Cell Biol 2002, 12:112-120.

101. Holmes KC, Popp D, Gebhard W, Kabsch W: Atomic model of the actin filament. Nature 1990, 347:44-49.

102. Cross AK, Woodroofe MN: Chemokines induce migration and changes in actin polymerization in adult rat brain microglia and a human fetal microglial cell line in vitro. J Neurosci Res 1999, 55:17-23.

103. Welch MD, Mullins RD: Cellular control of actin nucleation. Annu Rev Cell Dev Biol 2002, 18:247-288.

104. Faff L, Nolte C: Extracellular acidification decreases the basal motility of cultured mouse microglia via the rearrangement of the actin cytoskeleton. Brain Res 2000, 853:22-31.

105. Swanson JA: Shaping cups into phagosomes and macropinosomes. Nat Rev Mol Cell Biol 2008, 9:639-649.

106. Castellano F, Chavrier P, Caron E: Actin dynamics during phagocytosis. Semin Immunol 2001, 13:347-355.

107. Barcia C, Ros CM, Annese V, Carrillo-de Sauvage MA, Ros-Bernal F, Gomez A, Yuste JE, Campuzano CM, de Pablos V, Fernandez-Villalba E, Herrero MT: ROCK/Cdc42-mediated microglial motility and gliapse formation lead to phagocytosis of degenerating dopaminergic neurons in vivo. Sci Rep 2012, 2:809.

108. Swanson JA, Johnson MT, Beningo K, Post P, Mooseker M, Araki N: A contractile activity that closes phagosomes in macrophages. J Cell Sci 1999, 112(Pt 3):307-316.

109. Xiong Y, Coombes CE, Kilaru A, Li X, Gitler AD, Bowers WJ, Dawson VL, Dawson TM, Moore DJ: GTPase activity plays a key role in the pathobiology of LRRK2. PLoS Genet 2010, 6:e1000902.

110. Shin N, Jeong H, Kwon J, Heo HY, Kwon JJ, Yun HJ, Kim CH, Han BS, Tong Y, Shen J, Hatano T, Hattori N, Kim KS, Chang S, Seol W: LRRK2 regulates synaptic vesicle endocytosis. Exp Cell Res 2008, 314:2055-2065.
111. Yun HJ, Park J, Ho DH, Kim H, Kim CH, Oh H, Ga I, Seo H, Chang S, Son I, Seol W: LRRK2 phosphorylates Snapin and inhibits interaction of Snapin with SNAP-25. Exp Mol Med 2013, 45:e36.

112. Migheli R, Del Giudice MG, Spissu Y, Sanna G, Xiong Y, Dawson TM, Dawson VL, Galioto M, Rocchitta G, Biosa A, Serra PA, Carri MT, Crosio C, laccarino C: LRRK2 affects vesicle trafficking. Neurotransmitter extracellular level and membrane receptor localization. PLoS One 2013, 8:e77198.

113. MacLeod DA, Rhinn H, Kuwahara T, Zolin A, Di Paolo G, McCabe BD, Marder KS, Honig LS, Clark LN, Small SA, Abeliovich A: RAB7L1 interacts with LRRK2 to modify intraneuronal protein sorting and Parkinson's disease risk. Neuron 2013, 77:425-439

114. Ravikumar B, Imarisio S, Sarkar S, O'Kane CJ, Rubinsztein DC: Rab5 modulates aggregation and toxicity of mutant huntingtin through macroautophagy in cell and fly models of Huntington disease. J Cell SCi 2008, 121:1649-1660.

115. Stow JL, Manderson AP, Murray RZ: SNAREing immunity: the role of SNAREs in the immune system. Nat Rev Immunol 2006, 6:919-929.

116. Stanley AC, Lacy P: Pathways for cytokine secretion. Physiology (Bethesda) 2010, 25:218-229

117. Stow JL, Low PC, Offenhauser C, Sangermani D: Cytokine secretion in macrophages and other cells: pathways and mediators. Immunobiology 2009, 214:601-612.

118. Lucin KM, Wyss-Coray T: Immune activation in brain aging and neurodegeneration: too much or too little? Neuron 2009, 64:110-122.

119. Bucci C, Bakke O, Progida C: Rab7b and receptors trafficking Commun Integr Biol 2010, 3:401-404.

120. Stuart LM, Ezekowitz RA: Phagocytosis: elegant complexity. Immunity 2005, 22:539-550.

121. Imamura K, Hishikawa N, Sawada M, Nagatsu T, Yoshida M, Hashizume Y: Distribution of major histocompatibility complex class II-positive microglia and cytokine profile of Parkinson's disease brains. Acta Neuropathol 2003, 106:518-526.

122. Ghosh A, Roy A, Liu X, Kordower JH, Mufson EJ, Hartley DM, Ghosh S, Mosley RL, Gendelman HE, Pahan K: Selective inhibition of NF-kappaB activation prevents dopaminergic neuronal loss in a mouse model of Parkinson's disease. Proc Natl Acad Sci USA 2007, 104:18754-18759.

123. Taymans JM, Vancraenenbroeck $R$, Ollikainen $P$, Beilina A, Lobbestael $E$ De Maeyer M, Baekelandt V, Cookson MR: LRRK2 kinase activity is dependent on LRRK2 GTP binding capacity but independent of LRRK2 GTP binding. PLoS One 2011, 6:e23207.

doi:10.1186/1742-2094-11-52

Cite this article as: Russo et al:: LRRK2 and neuroinflammation: partners

in crime in Parkinson's disease? Journal of Neuroinflammation 2014 11:52.

\section{Submit your next manuscript to BioMed Central and take full advantage of:}

- Convenient online submission

- Thorough peer review

- No space constraints or color figure charges

- Immediate publication on acceptance

- Inclusion in PubMed, CAS, Scopus and Google Scholar

- Research which is freely available for redistribution 